\title{
Forming of Economic Policy of Slovakia Using Alternative Measurements
}

\author{
Andrea Vondrová ${ }^{1}$ and Matej Valach ${ }^{2}$ \\ Economics University of Bratislava, Faculty of National Economy, Department of Economic Policy, \\ Bratislava, Slovakia
}

${ }^{1}$ Contribution originated within the grant project VEGA No. 1/0795/12: The extended Leontief model with structural decomposition with the application on Slovak economy

${ }^{2}$ Contribution originated within the grant project VEGA No. 1/0570/11: Consumption and quality of life of households SR in relation to their consumer's decision-making in the European context

Correspondence should be addressed to: Andrea Vondrová; andrea.vondrova@euba.sk

Received date: 8 October 2013; Accepted date: 10 January 2014; Published date: 1 September 2014

Copyright (C) 2014. Andrea Vondrová and Matej Valach. Distributed under Creative Commons CC-BY 3.0

\begin{abstract}
In the global economy, the quantitative dimension of economic growth measured by GDP is necessary, but not sufficient to express the qualitative development of economy and society. Statisticians and economists recognized the need to provide policy makers and civil society with a reliable, timely and credible indicator that can quantitatively and qualitatively assess the current situation, which would also indicate prospects for further economic growth. The latest attempt at the international level to present the best of the range of comparable and comprehensive set of indicators of well-being is the Better Life Index, leading to attempting and finding a better way to measure growth and identifying key aspects necessary for prosperity. These aspects need to be known and used in decision-making processes in determining priorities and objectives of economic policy oriented so as to ensure not only the quantity but also the quality of economic growth and hence the quality of life.
\end{abstract}

Keywords: Economic policy, Alternative Measurements, Better Life Index,

\section{Introduction}

Since World War II, the dominant indicator of economic growth is the gross domestic product per capita (GDP), which is the market value of all officially recognized final goods and services produced within a country in a given period of time.
Economic growth is one of the most important economic categories at present. The quantitative dimension of economic growth as measured by GDP per capita is necessary, but not sufficient to measure the qualitative development of the society. Statisticians and economists recognize the need to provide policy makers and civil 
society with a reliable, timely and credible indicator that can quantitatively and qualitatively assess the current situation, which would also allow comparison between countries within the monitored time and would indicate prospects for further economic growth. The necessity and thinking about the future is more important when the world economy is still mired in the aftermath of the devastating crisis. Hesitant recovery, high unemployment, unprecedented volatility in financial markets and public debt force to think about defining the necessary policy responses in the long run.

Change in the qualitative shift of perception and measurement of economic growth does not mean that the GDP indicator should disappear, because it still provides answers to many important questions, but there should be still work on the development of the statistical system that complements the measures of market activities focusing on the human dimension and the dimension that affects a person's life quality. It should be noted that indicators to measure and compare the qualitative and quantitative dimensions of economic growth between countries are not created in order to brag, or determine the best, happiest, healthiest country or the worst, poorest, but they are rather created in order to define common objectives and measure the contribution of each country to the achievements of these societal goals. They should shape a comprehensive picture of well-being across economies with conditions of human life, which is reflected through the material conditions and quality of life. At the same time, these indicators respond to the needs of citizens to be better informed about their welfare and needs of policy makers to have a clearer picture of the economic, but also the social development.

\section{Alternative Methods of Measuring GDP}

Awareness of shortcomings and limits of economic growth measured by GDP and numerous qualitative factors and aspects of the development is necessary when representatives of the economic policy are assessing the economy. They cannot take only the rate of economic growth that can be quantitatively measured. They must take into account numbers of factors of non-economic nature which contribute not only to economic growth but also to a better quality of life of individuals and society.

All these limits constrain many economists and the various special groups to address the need to actively explore alternative methods which would take into account the qualitative aspects of growth and contribute to the elimination or adjustment of these deficiencies in the measurements. Alternative indicators can be divided into two groups depending on whether the indicator adjust or completes value of GDP or there are aggregate indices created to even replace the GDP.

The first comprehensive alternative to regulate the value of GDP is considered Measurement of Economic Welfare (MEW), which was introduced in 1972 by economists W. Nordhaus and J. Tobin. MEW took into account GDP calculation as a starting point, but the authors reclassified the final expenditure. GDP was adjusted by the amount of free time and the amount of unpaid work in the economy, which increases the value of GDP, and with the value of environmental damage caused by industrial production and consumption, which reduces the value of GDP. MEW is considered as a forerunner of later attempts to create sophisticated indicators, such as the Index of Sustainable Economic Welfare (ISEW), this indicator is very similar to Genuine Progress Indicator (GPI) and Sustainable Measurement of Economic Welfare (SMEW).

Economic Aspects of Welfare index (EAW) was created in 1981 by the economist X. Zoltas, who extended the measurement of GDP of social measures which he based on displaying a wide range of real changes in society which quantify well-being, regardless of whether these changes were the result of 
market transactions or not. The starting point, as opposed to MEW, were expenditures on private consumption, while various other values were added or subtracted depending on whether the positively or negatively affect economic prosperity, as with MEW. EAW differs from MEW to focus on actual flows of goods and services, and thus largely ignores the accumulation of capital and the issue of sustainability. EAW specifically addressed the question of damages on the environment as MEW.

J. Van der Bergh (2007) and E. Goossens et al . (2007) mentioned an alternative indicator, which is based on a modification of GDP, Adjusted net savings. It is an indicator used by the World Bank, which is based on the concept of real savings (Genuine savings).

Nearby, the points of parameters that govern GDP include e.g. the green GDP, which takes into account economic growth with environmental consequences, and especially trying to calculate the monetary value of biodiversity loss and the cost caused by climate change. The official EU document considers the term "green GDP" to be a wider concept, which concerns all indicators seeking to adjust GDP, which would capture the environmental or the social aspect of sustainable development.

The most common and well-known indicators that have been created with the ambition to replace GDP include the Human Development Index (HDI), Environmental Sustainability Index (ESI), an indicator of Ecological footprint, Environmental Performance Index (EPI), Gross National Happiness (GNH), Happy Planet Index (HPI), Index of Quality of Life (QOL) Index of Economic Well-being (IEWB), Index of Social Development (ISP), Index of Social Health or Better Life Index (BLI). Due to the vague theme, only some of these alternative approaches are mentioned. In this work, BLI will be discussed.

\section{CREATION OF BLI}

Since 2008, the Commission on the Measurement of Economic Performance and Social Progress (CMEPSP) has been established, which was the initiative of the French President N. Sarközy with the goal to solve the problem: "nothing is more destructive than the gap between people's perceptions of their own everyday economic well-being and what their politicians and statisticians say about their economy "(Sarközy, 2008).

The Commission was under the supervision of J. Stiglitz, A.K. Sen and J. P. Fitoussi. The goal was to identify the limits of GDP as an indicator of economic growth and social progress, and to consider any additional information necessary to create a more relevant indicator that could, with the most appropriate way, present the results, which would also serve to check the feasibility of measurement tools proposed by the Commission.

Stiglitz-Sen-Fitoussi report (the SSF report) pointed out that the statistical indicators are important for the design and evaluation of policies to promote the progress of the company, as well as to assess and influence the functioning of economic markets. The role of these indicators increased significantly in the last two decades, reflecting the improvement in the level of education, an increase in the complexity of modern economies and the widespread use of information technology.

The main benefit of SSF report, except the characterization of constraints GDP figures, is the creation of an overview of important ideas and concepts for sustainable economic development and the creation of 12 principles that should be followed while designing a comprehensive qualitative indicator of economic growth and development. Within these 12 principles is a major step distinction between the assessment of current well-being and sustainability. 
The authors of this report also stress the importance of objective and subjective wellbeing and the quality of life indicators which should take into account the social and economic inequalities between different socio-economic groups of the population. However, at the same time, we can conclude that they did not construct a comprehensive qualitative indicator of economic growth and development. However, the authors conclude how this indicator should be constructed. It should, therefore, ultimately be a combination of synthetic indicator of welfare state in units with a set of indicators reflecting the state of the natural environment expressed in different physical units.

Based on the success and benefits of SSF report, in 2011 Better Life Initiative was founded for the purpose of promoting economic prosperity, improving the prospects for development and welfare of the citizens. OECD here identified the key issues that are essential to the well-being of the individual in terms of material living conditions (housing, income, jobs) and quality of life (background, education, environment, governance, health, life satisfaction, safety and work life balance). Every single dimension is based on specific indicators. In this spirit, this initiative has released a publication titled "How's life? Measuring the well being". This publication is the first attempt at an international level to present the best set of comparable and comprehensive welfare indicators for developed and emerging economies. These variables were involved in a new interactive tool: Better Life Index.
The framework of this publication identifies three pillars for understanding and measuring the progress and well-being of people, they are:

○ Material living conditions,

- Quality of life,

- Sustainability.

This approach distinguishes between today's and tomorrow's prosperity. This means that primarily we have to determine the number of dimensions related to material living conditions and quality of life, and secondly the number of conditions that must be met in order to maintain the well-being of future generations. BLI consists of 11 dimensions that reflect what the OECD considers essential. Each dimension is based on one to three specific parameters.

\section{The Values of Better Life index of Slovakia}

On the next page we can monitor on Fig 1, the value of BLI in the year 2012 varies between countries from the level of 0.24 in Russia after 0.71 in Denmark. OECD average is at 0.58. The value of BLI of the Slovak Republic reaches a value of 0.47 , which we can conclude is not even the OECD average. To be able to determine the basis of this index in SR compared to those other countries that are lagging behind, and thereby specify which areas Slovakia's economic policy should focus on, we must evaluate the individual sub-indices separately, as the resulting index says nothing about the values in which we achieve higher or lower levels. The final index is determined only by the ranking of countries and does not have any other information value. 


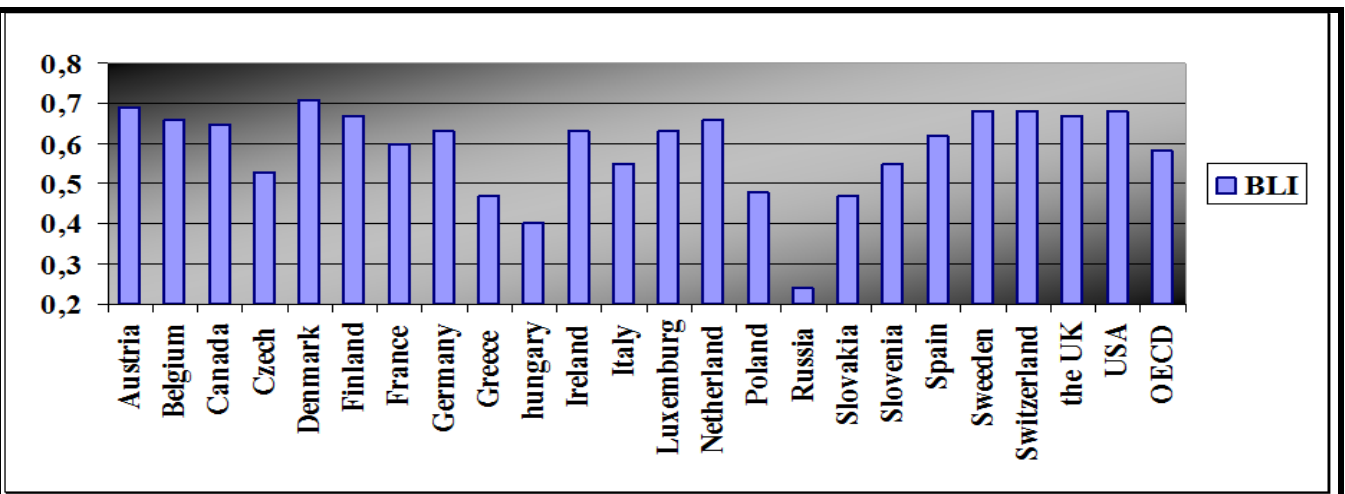

Figure 1: LI for individual countries in year 2012

Looking at the individual sub-indices, we can conclude that Slovakia lags behind in almost all areas according to OECD average values. Only in two dimensions, out of 11 , SR has a higher value than the average values, at a dimension of personal security and social relations. The rest of these areas are well below the OECD average value, as shown in Fig 2. The worst results are obtained in dimensions that most directly affect the quality of life of citizens, namely the level of income and wealth of the population and the quality of working conditions and life balance.

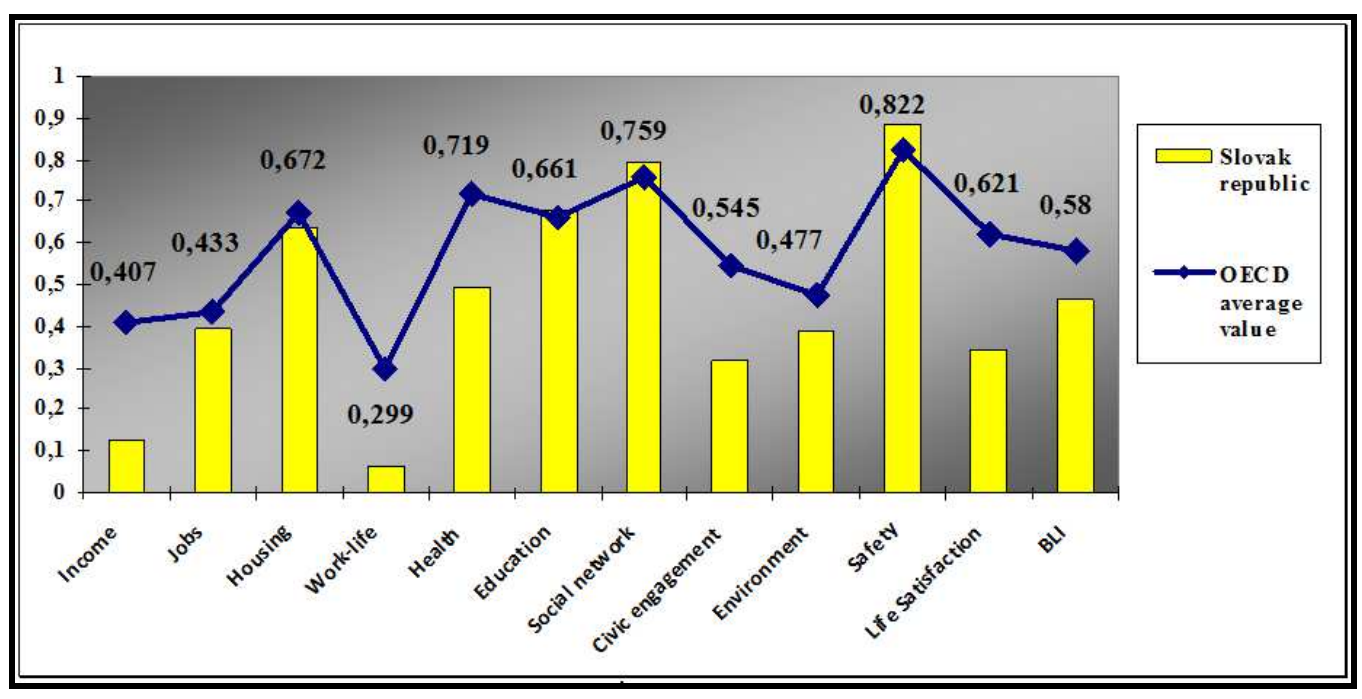

Figure 2: BLI for Slovakia and the OECD average value

Based on the construction of the alternative indicator BLI, we can conclude that this is a good method of feasibility of using the alternative indicator to identify areas that Slovakia's economic policy should aim at, improving the welfare of citizens. Based on the identification of those dimensions, in which Slovakia lags behind the OECD average, we can formulate the objectives of economic policy and also tools that should be used to achieve them.

Based on the outcomes, it can be demonstrated that the representatives of 
economic policy should ensure continuous and sustainable economic growth, achieving a competitive real economy in the global space, which is not based on cheap labor, the uncertainty in labor relations, which derives its global competitiveness from the employees who are familiar with the world's most advanced technologies, methods and techniques witch they can use flexibly with effective public administration, which forms the basic framework for the stability of the business environment operates in a stable legal environment that is respected and is enforceable and improved by the open and equal social dialogue.

The government should be built on the belief that the economic prosperity of Slovakia and its sustainable economic growth is possible through the overall convergence of the economy to the developed EU countries while maintaining a sufficient level of socioeconomic cohesion. It is all about stability, favorable business environment and growth of competitiveness.

The economic crisis has not only necessitated significant resources to mitigate its negative effects, but also revealed some debts of existing development. Among the prerequisites for economic development is increasing public sector efficiency while maintaining the core values of the solidarity and cohesion, the implementation of which is essential not for only economic development but also its sustainability.

The particular development of economic growth, public finances and unemployment suggests that the impact of the global crisis was reflected in higher costs for stable economic growth to provide the necessary socio-economic cohesion better than it was before the crisis. Therefore, it is necessary to put increased demands on management efficiency and effectiveness of economic policy measures in terms of sustainability of public finances.

The main tool to achieve balanced and sustainable development of the national economy is the financial and economic policy, solving those aspects of finance and the real economy, which determine the nature of further development of Slovakia. These policies should therefore be designed to be further enhanced by the constitutional value orientation of Slovakia for sustainable social and environmental development of the market economy and the strengthening certainties of life of its inhabitants.

The government should base itself on the results of BLI considered in the process of sustainable development in the national interest SR achievement and the maintenance of the high quality of environment protection and rational use of natural resources. A key and vital tool for sustainable development should consider the orientation of economic development for consistent production, which is consistent with both sides, as the ecological requirements of the company. Special care should be given to the use of available labor in regions with underdeveloped environmental infrastructure.

At the same time, the aim should be focusing on the optimization of spatial arrangement and functional use of land, protection of natural and cultural heritage, building environmental monitoring and information system, raising environmental awareness and awareness of the environmental situation. This means that it is necessary to achieve rational use and protection of natural resources - water, soil, air, rocks, wild animals and wild plants.

At the same time, the government should pay the rational use of domestic raw materials and promote the development of businesses that use them and the technology of mining, and adjustments do not affect negatively on the environment. The basic starting point in eliminating environmental risks should check environmental safety, greening buildings, equipment and products. 


\section{Conclusions}

In order to economic growth do not become just vague concept, we need a tool that will measure whether the country has moved towards long-term sustainable development or, on the contrary, the situation in the country deteriorates, and also whether development is the result of changes in the quantitative dimensions, or is the result of qualitative changes. There exists a long-term effort of numerous economists in collaboration with experts from other professions to develop an alternative indicator, which is more credible and reflects the development not only in economic performance. If you want to fill those needs in terms of social inclusion of synthetic analysis, it is necessary to establish a comprehensive index, which also allows a comparison between countries. Making these types of indexes currently flourishing as social and environmental statistics have become more readily available and the measurement is becoming increasingly easier.

The latest attempt at the international level to present the best of the range of comparable and comprehensive welfare indicators for developed and emerging economies is a set of indicators involved in the Better Life Index. Under this initiative, the statistics on the critical aspects of human life are important, is not enough in itself, and it is essential to be combined with an understanding and analysis of these outcomes, as measured by these indicators, responding to political action.

The evaluation of the results of an alternative indicator of SR compared with OECD countries suggests that the key issue for further development of the Slovak Republic gradually eliminates the gaps in various aspects of the qualitative dimension. In terms of the qualitative dimension of economic growth, entering

the BLI, a top priority of government economic policy should become a positive influence on productivity and dimension wages and jobs.

Influencing wages may lead to labor productivity growth, which can increase real wages and the living standards of the population, and thereby increasing the dimension of the subjective perception of well-being. It must, however, choose the correct economic policy, because if there would be wage pressures, and wages would rise faster than productivity, it could decrease the competitiveness of enterprises, which will result in layoffs and consequently the growth of unemployment, and this would decrease in negative influence in all these dimensions of human well-being.

The second recommended dimensions that Slovakia's economic policy should address are a dimension of education. For influencing education, they should simultaneously accompany economic policy actions and measures to encourage the growth of technological productivity, enabling revenue growth of population. Among others, economic policy recommendations are necessary for the effective operation and use of alternative indicators to accept the need for a more flexible labor market, allowing greater mobility of labor, and hence faster adjustment of demand and supply shocks.

As we can see on the previous results of BLI for SR, these 11 dimensions actually refer to those in which Slovakia lags behind. It is on representatives of economic policy to take the results into account when determining the objectives and instruments used to achieve goals in practice. At the same time, the results of an alternative indicators result in the gradual implementation of this indicator in the development of objectives and instruments, because based on the observed alternative measurements we can conclude that we can identify exactly where the dimensions of human welfare of SR are lagging behind compared to developed countries, and so we could pick the right economic policy that will be as effective as possible in the country. 
The use of the mentioned alternative indicator or any other alternative indicator in assessing the economic performance of individual countries is a qualitative step forward, but there are still qualitative dimensions of life that are not included in the measurements. This fact creates a space for the construction of additional indicators or the expansion of existing ones that could comprehensively assess the quality of life.

\section{References}

1. Blyes, B. 2006 'The Index of Sustainable Economic Welfare for Belgium. Data, Methodology and Preliminary Results', [Online] Brussel: Slobodná Univerzita 2006. [Retrieved December 17, 2012] http://www.statbel.fgov.be

2. Commission on the measurement of economic performance and social progress. 2009 Stiglitz-Sen-Fitoussi Report. [Online] [Retrieved December 17, 2012] http://www.stiglitz-sen-

fitoussi.fr/en/index.htm

3. Daly, H. and Cobb, J. 1989 For the Common Good. Redirecting the Economy toward Community, the environment and a Sustainable Future. 2nd. Edition. Boston: Beacon Press, s. 79. ISBN 0807047058.

4. England, R. W. and Harris, J. M. 1998 Alternatives to Gross National Product (A Critical Survey). Medford (Massachusetts, USA): Tufts University

5. European statistical system, 2011 'Sponsorship Group on Measuring Progress, Well-being and Sustainable Development', Final report, November 2011, [Online] [Retrieved November 10,2012] http://epp.eurostat.ec.europa.eu/portal/pag e/portal/pgp_ess/about_ess/measuring_pro gress

6. Goosens, Y. a kol. 2007 'Alternative progress indicators to Gross Domestic Product (GDP) as a means towards sustainable development', [Online].
Luxemburg: European parliament, [Retrieved January 22, 2013] http://www.europarl.europa.eu

7. Meadows, D.H. and Randers, J., Meadows, D.L. 2004 Limits to Growth: The 30-Year Update. USA: Chelsea Green Publishing Company. ISBN 1-9311498-51-2.

8. Nordhaus, W. D. and Tobin,. J. 1972 'Is Growth Obsolete?' In: Economic Growth, National Bureau of Economic Research, General Series No. 96, New York, s. 1 - 80.

9. OECD, 2011 Better life initiative, [Online] Compendium of OECD Well-being Indicators. [Retrieved January 22, 2013] http://www.oecd.org/std/47917288.pdf

10.0ECD, 2011 Better life initiative, [Online] How's life? Measuring the well being. [Retrieved January 22, 2013] http://www.oecd.org/statistics/measuringw ell-beingandprogress.htm

11.OECD, 2011 Better life initiative, [Online] OECD Work On Measuring Well-Being and Progress towards Green Growth. [Retrieved January 22, 2013] http://www.oecd.org/std/rioplus20\%20to\% 20print.pdf

12. Osberg, L. and Sharpe, A. 2002 An Index of Economic Well-Being for Selected OECD Countries. In Review of Income and Wealth. Series 48. no.3.

13. Wackernagel, L.W. and Rees, W. 1996 Our Ecological Footprint: Reducing Human Impact on the Earth. Canada - Gabriela Island: New Society Publisher, ISBN: 086971-312-X 